This is the "Authors Accepted Manuscript" of an article published in: Journal of Crystal Growth, Volume 312, Issue 9, 15 April 2010, Pages 1475-1480.

The final version may be found at: https://doi.org/10.1016/j.jcrysgro.2010.01.026

\title{
Self-catalyzed Growth of GaSb Nanowires at Low Reaction Temperatures
}

Stephan Schulz, ${ }^{*}, a$ Marcel Schwartz, ${ }^{a}$ Andreas Kuczkowski, ${ }^{a}$ and Wilfried Assenmacher ${ }^{b}$

a Chemistry Department and Center for Nanointegration Duisburg-Essen (CeNIDE), University of Duisburg-Essen, Universitätsstr. 5-7, D-45117 Essen, Germany.

Phone: 49201 1834635; Fax: 49201 1833830; E-mail: stephan.schulz@uni-due.de

${ }^{\mathrm{b}}$ Chemistry Department, University of Bonn, Römerstr. 164, D-53117 Bonn, Germany.

\section{Summary}

Thermal decomposition of Lewis acid-base adducts $\left[t-\mathrm{Bu}_{3} \mathrm{Ga}-\mathrm{Sb} i-\mathrm{Pr}_{3}\right]$ (1) and $[t-$ $\mathrm{Bu}_{3} \mathrm{Ga}_{2}\left[\mathrm{Sb}_{2} \mathrm{Et}_{4}\right]$ (2) in closed glass ampoules at temperatures between 250 to $350{ }^{\circ} \mathrm{C}$ yielded crystalline $\mathrm{GaSb}$ nanowires. Isolated $\mathrm{GaSb}$ nanowires were formed preferably at low decomposition temperatures, whereas dendritic-like growth was observed at higher decomposition temperatures. In addition, self-catalyzed growth of GaSb nanowires using 90 nm-sized Ga droplets, which were pre-deposited on $\mathrm{Si}(100)$ substrates, was achieved with the distibine $\mathrm{Sb}_{2} \mathrm{Et}_{4}$ at $250{ }^{\circ} \mathrm{C}$.

Keywords: GaSb, Nanowire, MOCVD

This work may be used under a Creative Commons Attribution NonCommercial - NoDerivatives 4.0 License (CC BY-NC-ND 4.0) 


\section{Introduction}

The synthesis of semiconducting nanowires has received increasing interest in the last decade due to their advantageous physical properties,[1] which render them very promising for potential applications in nanoelectronics and optoelectronics.[2] They are typically grown by chemical beam epitaxy (CBE),[3] molecular beam epitaxy (MBE),[4] laser catalytic growth (LCG),[5] chemical vapor deposition (CVD)[6] and metal-organic vapor phase epitaxy (MOVPE).[7] In MOCVD processes, a Au-nanoparticle typically serves as preferential site for adsorption of the reactant(s) and nucleation site for the nanowire growth according to the so-called vapor-liquid-solid (VLS) mechanism.[8] The diameter of the nanowire is typically controlled by the size of the droplets, even though the role of the size of the catalytic particle is lively discussed[9] and a rather more complex growth mechanism is assumed nowadays.[10] For instance, a recent study of Seifert et al. on the growth of III-V nanowires clearly showed that the Au particle is not inert with respect to the III-V material as was assumed. Instead, the Au particle is rather in the solid III-V phase during nanowire growth than in the liquid phase.[11]

Most of the work in nanowire growth has focused on the growth of wide band gap III$\mathrm{V}$ materials with optical transitions in the UV-visible-blue wavelength range.[12] In contrast, nano-sized III-V materials operating in the infrared regime have been investigated to a far lesser extent. Group III-antimonides are well-established materials for mid-wave and longwave infrared (IR) detection applications due to their small band gaps (AlSb $1.60 \mathrm{eV}, \mathrm{GaSb}$ $0.72 \mathrm{eV}$; InSb $0.17 \mathrm{eV}$ ) and high carrier motilities', respectively.[13] Moreover, their small effective masses and large mean-free paths render these nanowires very interesting for studying quantum confinement effects.[14] Despite the growing interest in antimonide semiconductors, the synthesis of one-dimensional structures of $\mathrm{GaSb}$ and $\mathrm{InSb}$ has not been reported extensively in the literature. Only very recently, a very few studies on the growth of $\mathrm{GaSb}$ and InSb nanowires by Au-assisted MOCVD,[15] antimonidization of Ga droplets,[16] electrodeposition in porous templates,[17] and by a focused ion beam approach have been reported.[18]

We have demonstrated in the past that GaSb nanowires can be obtained by thermal decomposition of a so-called single source precursor in closed glass ampoules.[19] Herein we report on our detailed studies concerning the influence of the type of precursor as well as the particular decomposition temperature on the nanowire growth. Moreover, we have investigated the self-catalyzed growth of GaSb nanowires on $\mathrm{Si}(100)$ substrates using predeposited Ga metal droplets as seeds for GaSb nanowire growth. 


\section{Experimental Section}

\section{Pyrolysis of $t-B u_{3} G a-S b(i-P r)_{3}(1)$ and $\left[t-B u_{3} G a\right]\left[S b_{2} E t_{4}\right]_{2}$ (2)}

Precursor (1)[20] (15 mg) or (2)[21] (20 mg) was sealed under an Ar-atmosphere in a glass ampoule, which was then heated with a heating rate of $50{ }^{\circ} \mathrm{C} / \mathrm{h}$ to the desired decomposition temperature $\left(\mathrm{T}_{d e c}\right)$. Heating was maintained for $3 \mathrm{~h}$ at this specific temperature, followed by cooling to ambient temperature with a cooling rate of $50{ }^{\circ} \mathrm{C} / \mathrm{h}$. The ampoules are covered inside with a dark gray, shiny material film.

\section{Self-catalyzed growth of GaSb nanowires}

Ga droplets were deposited on $\operatorname{Si}(100)$ substrates $\left(\mathrm{T}_{\text {substrate }}=400{ }^{\circ} \mathrm{C}\right)$ in a home-made cold wall reactor by thermal decomposition of $t-\mathrm{Bu}_{3} \mathrm{Ga}$, which was introduced using $\mathrm{Ar}$ as carrier gas $\left(10 \mathrm{sccm}, \mathrm{t}_{\text {dep }}=5 \mathrm{sec}\right)$. After the substrate was cooled to $250{ }^{\circ} \mathrm{C}, \mathrm{Sb}_{2} \mathrm{Et}_{4}$ was introduced into the reactor by use of argon carrier gas $(30 \mathrm{sccm})$ with different deposition times ( $\left.\mathrm{t}_{\text {dep. }}=90-120 \mathrm{~min}\right)$.

\section{Material Characterization}

Scanning electron microscopy studies (SEM) were carried out either on a Philips XL20 (W-filament), equipped with an energy dispersive X-ray spectroscopy (EDX) device (Noran Voyager, Si(Li)), or an ESEM Quanta 400 FEG. Pieces of the broken glass tube covered with the GaSb material were typically sputtered with a thin gold film to improve the conductivity and therefore the contrast of the material film.

Transmission electron microscopy studies (TEM) were performed either on a Philips CM30ST (LaB 6 -cathode) at $300 \mathrm{keV}$ or on a Philips CM300UT (FEG) at $297 \mathrm{keV}$, both equipped with a HP-Ge EDX-detector (Noran Voyager) for EDX-analysis. Sb-L and Ga-K lines were used for quantification of the EDX-data. The $\mathrm{Sb} / \mathrm{Ga}$ ratio was determined using the "Metal-Thin-Foil-Method" with $k$-factors (Cliff-Lorrimer method), which were obtained from calibration of the EDX-system with certified GaSb from Aldrich chemical company. The samples were prepared on perforated carbon foils without further grinding.

\section{Results and Discussion}

$t$ - $\mathrm{Bu}_{3} \mathrm{Ga}-\mathrm{Sb}(i-\mathrm{Pr})_{3}$ (1) was decomposed in closed glass ampoules at temperatures between 250 and $350{ }^{\circ} \mathrm{C}$, respectively. Typical SEM images of samples obtained at $275^{\circ} \mathrm{C}$, $300{ }^{\circ} \mathrm{C}$ and $325^{\circ} \mathrm{C}$ are shown in Figure 1.

\section{((Figure 1 here))}

Two SEM images obtained at different magnifications are presented for each sample, clearly demonstrating the formation of isolated nanowires even at very low reaction 
temperatures $\left(\mathrm{T}_{\text {dec. }}=275{ }^{\circ} \mathrm{C}\right)$. Dendritic-like growth of nanowhiskers as was previously reported was not observed under these conditions,[19] clearly revealing the strong influence of the reaction temperature on the nanowire growth. Small Ga droplets at the tips of the wires prove the vapor-liquid-solid (VLS)-growth mechanism.[22] The Ga droplets are formed by thermal decomposition of $t-\mathrm{Bu}_{3} \mathrm{Ga}$, which is easily formed in situ under the reaction conditions by dissociation reaction of the starting Lewis acid-base adduct $t-\mathrm{Bu}_{3} \mathrm{Ga}-\mathrm{Sb}(i-\mathrm{Pr})_{3}$ 1. The Ga droplets then catalyze the decomposition of $i-\mathrm{Pr}_{3} \mathrm{Sb}$ by reducing its decomposition temperature and serve as solvent for as-formed $\mathrm{Sb}$. After the $\mathrm{GaSb}$ alloy supersaturates with antimony, the growth of single GaSb nanowires starts at the interface between the liquid and the solid phase. The low reaction temperatures prevent dendritic-like growth as is typical for higher temperatures. EDX and SAED studies prove the formation of crystalline GaSb (sphalerit type).

\section{((Figure 2 here))}

In order to verify the general applicability of the described decomposition process for the formation of $\mathrm{GaSb}$ nanowires, we became interested in the decomposition behavior of other types of $\mathrm{Sb}$ precursors. Distibines of the general type $\mathrm{Sb}_{2} \mathrm{R}_{4}^{\prime}$, which contain a central Sb$\mathrm{Sb}$ bond, are known to tend to undergo $\mathrm{Sb}-\mathrm{Sb}$ bond dissociation reactions even at low temperatures due to the rather weak $\mathrm{Sb}-\mathrm{Sb}$ bond. However, we have recently synthesized several Lewis acid-base adducts of the type $\left[\mathrm{R}_{3} \mathrm{Ga}_{2}\left[\mathrm{Sb}_{2} \mathrm{R}_{4}^{\prime}\right]\right.$ by reaction of the distibine $\mathrm{Sb}_{2} \mathrm{R}_{4}{ }_{4}$ with a twofold excess of the corresponding gallane $\mathrm{R}_{3} \mathrm{Ga}$, demonstrating that these type of Lewis acid-base adducts are stable compounds at low temperature.[21,23] [t$\left.\mathrm{Bu}_{3} \mathrm{Ga}\right]_{2}\left[\mathrm{Sb}_{2} \mathrm{Et}_{4}\right] 2$ was chosen as a promising precursor for decomposition studies since this adduct is easy accessible[21] and the donor-acceptor (Sb-Ga) interaction (bond strength) is expected to be rather low, hence allowing the complex to dissociate in the gas phase at relatively low temperatures. Moreover, the pure distibine $\mathrm{Sb}_{2} \mathrm{Et}_{4}$ was recently been shown by mass spectroscopy to undergo disproportionation reactions in the gas phase at relatively low temperatures $\left(\mathrm{T}_{\text {dec. }}=100-250{ }^{\circ} \mathrm{C}\right.$; activation energy $\left.183 \mathrm{~kJ} / \mathrm{mol}\right)[24]$ with subsequent formation of elemental antimony and the corresponding trialkylstibine $\mathrm{SbEt}_{3},[25]$ which is stable under these specific conditions up to $400{ }^{\circ} \mathrm{C}$ as was found by us and others.[26]

Decomposition studies were performed in closed glass ampoules in the temperature range between 250 and $350{ }^{\circ} \mathrm{C}$. Again, the influence of the reaction temperature can clearly be seen. Isolated crystalline GaSb nanowires are predominantly formed at lower reaction temperatures as was observed for precursor $\mathbf{1}$. However, in contrast to $\mathbf{1 , 2}$ tends to dendriticlike whisker growth at higher decomposition temperatures $\left(350{ }^{\circ} \mathrm{C}\right)$ as can clearly be seen 
when comparing the TEM images of two samples that were scratched from the ampoule wall and deposited on the carbon grid.

\section{((Figure 3 here))}

These results clearly indicate that the decomposition of the distibine $\mathrm{Sb}_{2} \mathrm{Et}_{4}$ occurs much faster at $350{ }^{\circ} \mathrm{C}$ compared to the stibine $i$ - $\mathrm{Pr} 3 \mathrm{Sb}$, most likely due to the weak $\mathrm{Sb}-\mathrm{Sb}$ bond. As a consequence, the Sb-concentration in the GaSb alloy increases much faster, hence forcing the whisker growth. SAED as well as HRTEM studies clearly proved the nanowires to be crystalline, which is remarkable with respect to the low decomposition temperature of 250 ${ }^{\circ} \mathrm{C}$.

\section{((Figure 4 here))}

These promising results prompted our interest toward a rather controlled growth of $\mathrm{GaSb}$ nanowires and we started to investigate the possibility of a self-catalyzed growth of GaSb. The pyrolysis experiments clearly showed that Ga droplets act as an initiator (catalyst) for the GaSb nanowire growth. Ga droplets have been shown in the past to initiate nanowire growth of a variety of materials such as Si and Ge.[28] Therefore we became interest in the deposition of small $\mathrm{Ga}$ droplets with a defined diameter. $t$ - $\mathrm{Bu}_{3} \mathrm{Ga}$ was chosen as a suitable $\mathrm{Ga}$ source due to the rather weak Ga-C bonds. Deposition studies on $\mathrm{Si}(100)$ substrates in a home-made cold wall reactor clearly showed that the formation of Ga droplets strongly depends on the substrate temperature and the deposition time. Ga droplets with only a small size distribution $\left(\varnothing_{a v} .90 \mathrm{~nm}\right)$ were obtained at $400{ }^{\circ} \mathrm{C}$ and short deposition times $\left(\mathrm{t}_{\text {dep. }}=5\right.$ $\mathrm{sec})$, whereas longer deposition times $\left(\mathrm{t}_{\text {dep. }}=10 \mathrm{sec}\right)$ and higher substrate temperatures $\left(\mathrm{T}_{\text {substrate }}=500{ }^{\circ} \mathrm{C}\right)$ yielded much larger $\mathrm{Ga}$ droplets. The formation of droplets with homogeneous diameters is crucial since the effective band gap of a given nanowire depends on its size as was recently shown for GaAs nanowires.[29]

\section{((Figure 5 here))}

Initial CVD studies using as-prepared substrates and $\mathrm{Sb}_{2} \mathrm{Et}_{4}$ as $\mathrm{Sb}$-source were again performed in the temperature range between 250 to $350{ }^{\circ} \mathrm{C}$. These temperatures are significantly lower compared to the substrate temperatures typically realized in $\mathrm{GaSb}$ MOCVD film growth processes $\left(\mathrm{T}_{\text {substrate }}=450-500{ }^{\circ} \mathrm{C}\right)$, hence depressing the formation of $\mathrm{GaSb}$ films on the substrate.[15] Figure 6 shows GaSb nanowires obtained at a substrate temperature of $250^{\circ} \mathrm{C}$ and deposition times of 90 and 120 minutes, respectively.

\section{((Figure 6 here))}

The substrate is covered with tapered GaSb nanowires, which show typical lengths of $300\left(\mathrm{t}_{\text {dep }} .\left(\mathrm{Sb}_{2} \mathrm{Et}_{4}\right)=90 \mathrm{~min}\right)$ to $500 \mathrm{~nm}\left(\mathrm{t}_{\text {dep }} .\left(\mathrm{Sb}_{2} \mathrm{Et}_{4}\right)=120 \mathrm{~min}\right)$ and diameters of about $30-100$ 
$\mathrm{nm}$, whereas no GaSb film growth was observed. The diameters of the GaSb nanowires decrease with increasing length, which is in contrast to GaSb nanowires reported by Jeppson et al. ${ }^{[15 a, b]}$ Growth of tapered III-V nanowires was typically observed at high growth temperatures such as $450-500{ }^{\circ} \mathrm{C}$ as reported for $\mathrm{SbMe}_{3}$ (TMSb).[30] However, the GaSb nanowires reported herein were grown at a substrate temperature of $250{ }^{\circ} \mathrm{C}$. The most likely reason for their formation is the higher reactivity of the Sb-precursor $\mathrm{Sb}_{2} \mathrm{Et}_{4}$, which decomposes at significantly lower temperatures compared to TMSb.

Conclusion. Lewis acid-base adducts $\left[t-\mathrm{Bu}_{3} \mathrm{Ga}-\mathrm{Sb} i\right.$ - $\left.\mathrm{Pr}_{3}\right](\mathbf{1})$ and $\left[t-\mathrm{Bu}_{3} \mathrm{Ga}_{2}\left[\mathrm{Sb}_{2} \mathrm{Et}_{4}\right]\right.$ (2) can be used for $\mathrm{GaSb}$ nanowire growth in closed glass ampoules at low reaction temperatures between 250 and $350{ }^{\circ} \mathrm{C}$. Moreover, the present study demonstrate for the first time that distibines such as $\mathrm{Sb}_{2} \mathrm{Et}_{4}$ are promising precursors for the Ga-assisted growth of tapered $\mathrm{GaSb}$ nanowires at substrate temperatures as low as $250{ }^{\circ} \mathrm{C}$. For this purpose, Ga-droplets of uniform size $\left(\varnothing_{a v} .90 \mathrm{~nm}\right)$ were pre-deposited on $\mathrm{Si}(100)$ substrates by thermal decomposition of $t-\mathrm{Bu}_{3} \mathrm{Ga}$ at a substrate temperature of $400{ }^{\circ} \mathrm{C}$.

Acknowledgment. Stephan Schulz gratefully acknowledges financial support by the DFG.

\section{References}

[1] T.J. Trentler, K.M. Hickman, S.C. Goel, A.M. Viano, P.C. Gibbons, W.E. Buhro, Science 270 (1995) 1791;

A.M. Morales, C.M. Lieber, Science 279 (1998) 208;

M.K. Sunkara, S. Sharma, R. Miranda, G. Lian, E.C. Dickey, Appl. Phys. Lett. 79 (2001) 1546 ;

J.H. Lee, Z.M. Wang, Z.Y. AbuWaar, G.J. Salamo, Cryst. Growth \& Design 9 (2009) 715.

[2] P.D. Yang, MRS Bull. 30 (2005) 85;

Y. Huang, X.F. Duan, C.M. Lieber, Small 1 (2005) 142.

[3] B.J. Ohlsson, M.T. Björk, M.H. Magnusson, K. Deppert, L. Samuelson, L.R. Wallenberg, Appl. Phys. Lett. 79 (2001) 3335.

[4] S.K. Chan, Y. Cai, I.K. Sou, N. Wang, J. Crystal Growth 278 (2005) 146.

[5] A.M. Morales, C.M. Lieber, Science 279 (1998) 208;

X.F. Duan, C.M. Lieber, Adv. Mater. 12 (2000) 298;

M.S. Gudiksen, C.M. Lieber, J. Am. Chem. Soc. 122 (2000) 8801. 
[6] Y. Wu, Y. Cui, L. Huynh, C.J. Barrelet, D.C. Bell, C.M. Lieber, Nano Lett. 4 (2004) 433.

[7] W. Seifert, M. T. Borgström, K. Deppert, K.A. Dick, J. Johansson, M.W. Larsson, T. Martensson, N. Sköld, C.P.T. Svensson, B.A. Wacaser, L.R. Wallenberg, L. Samuelson, J. Crystal Growth 272 (2004) 211.

[8] R.S. Wagner, W.C. Ellis, Appl. Phys. Lett. 4 (1964) 89.

[9] B.A. Wacaser, K.A. Dick, J. Johansson, M. T. Borgström, K. Deppert, L. Samuelson, Adv. Mater. 21 (2009) 153;

M. T. Borgström, G. Immink, B. Ketelaars, R. Algra, E.P.A.M. Bakkers, Nature Nanotech. 2 (2007) 541.

[10] S.N. Mohammad, Nano Lett. 8 (2008) 1532;

[11] K.A. Dick, K. Deppert, L.S. Karlsson, L.R. Wallenberg, L. Samuelson, W. Seifert, Adv. Funct. Mater. 15 (2005) 1603.

[12] M.H. Huang, S. Mao, H. Feick, H. Yan, Y. Wu, H. Kind, E. Weber, R. Russo, P. Yang, Science 292 (2001) 1897;

X. Duan, Y. Huang, R. Agarwal, C.M. Lieber, Nature 421 (2003) 241;

J.C. Johnson, H. Yan, P. Yang, R.J. Saykally, J. Phys.Chem. B 107 (2003) 8816;

D. Dalacu, A. Kam, D.G. Austing, X. Wu, J. Lapointe, G.C. Aers, P.J. Poole, Nanotechnology 20 (2009) 395602.

[13] S. Dutta, H.L. Bhat, V. Kumar, J. Appl. Phys. 81 (1997) 5821;

I. Vurgaftman, J.R. Meyer, L.R. Ram-Mohan, J. Appl. Phys. 89 (2001) 5815;

A.H. Chin, S. Vaddiraju, A.V. Maslov, C.Z. Ning, M.K. Sunkara, M. Meyyappan, Appl. Phys. Lett. 88 (2006) 163115-1.

[14] L.R. Windmiller, Phys. Rev. 149 (1966) 472;

T.E. Huber, M.J. Graf, C.A. Foss, Jr., P. Constant, J. Mater. Res. 15 (2000) 1816;

Y.M. Lin, S.B. Cronin, J.Y. Ying, M.S. Dresselhaus, J.P. Heremans, Appl. Phys. Lett. 76 (2000) 3944;

J.P. Heremans, C.M. Thrush, Y.M. Lin, S. Cronin, Z. Zhang, M.S. Dresselhaus, J.F. Mansfield, Phys. Rev. B 61 (2000) 2921.

[15] M. Jeppsson, K.A. Dick, J.B. Wagner, P. Caroff, K. Deppert, L. Samuelson, L.-E. Wernersson, J. Crystal Growth 310 (2008) 4115;

M. Jeppsson, K.A. Dick, H.A. Nilsson, N. Sköld, J.B. Wagner, P. Caroff, L.-E. Wernersson, J. Crystal Growth 310 (2008) 5119;

P. Caroff, J.B. Wagner, K.A. Dick, H.A. Nilsson, M. Jeppsson, K. Deppert, L. Samuelson, L. Reine Wallenberg, L.-E. Wernersson, Small 4 (2008) 878. 
[16] S. Vaddiraju, M.K. Sunkara, A.H. Chin, C.Z. Ning, G.R. Dholakia, M. Meyyappan, J. Phys. Chem. C 111 (2007) 7339.

[17] X. Zhang, Y. Hao, G. Meng, L. Zhang, J. Electrochem. Soc. 152 (2005) C664.

[18] A. Lugstein, J. Bernardi, C. Tomastik, E. Bertagnolli, Appl. Phys. Lett. 88 (2006) 163114-1.

[19] A. Kuczkowski, S. Schulz, W. Assenmacher, J. Mater. Chem. 11 (2001) 3241.

[20] S. Schulz, M. Nieger, J. Chem. Soc. Dalton Trans. (2000) 639.

[21] A. Kuczkowski, S. Schulz, M. Nieger, Organometallics 20 (2001) 2000.

[22] Y. Wu, P. Yang, J. Am. Chem. Soc. 123 (2001) 3165. The VLS mechanism was confirmed at the nanometer scale by direct, in-situ observation of nanowire growth in a transmission electron microscope at high temperatures.

[23] A. Kuczkowski, S. Fahrenholz, S. Schulz, M. Nieger, Organometallics 23 (2004) 3615;

D. Schuchmann, A. Kuczkowski, S. Fahrenholz, S. Schulz, U. Flörke, Eur. J. Inorg. Chem. (2007) 931.

[24] N. Bahlawane, F. Reilmann, L.-C. Salameh, K. Kohse-Höinghaus, J. Am. Soc. Mass Spectrom. 19 (2008) 947.

[25] N. Bahlawane, F. Reilmann, S. Schulz, D. Schuchmann, K. Kohse-Höinghaus, J. Am. Soc. Mass Spectrom. 19 (2008) 1336.

[26] D.F. Grishin, V.K. Cherkasov, V.A. Dodonov, Izv. Akad. Nauk, Ser. Khim. (1994) 916

G.P. Smith, R. Patrick, Int. J. Chem. Kinet. 15 (1983) 167.

[27] Program used for simulation was published in: P.A. Stadelmann, Ultramicroscopy 21 (1987) 131; JEMS-ENS CIME EPFL, Lausanne, 2005.

[28] H. Chandrasekaran, G.U. Sumanasekara, M.K. Sunkara, J. Phys. Chem. B 110 (2006) 18351.

[29] F. Wang, H. Yu, S. Jeong, J.M. Pietryga, J.A. Hollingsworth, P.C. Gibbons, W.E. Buhro, ACS Nano 2 (2008) 1903.

[30] K. Hiruma, M. Yazawa, K. Haraguchi, K. Ogawa, T. Katsuyama, M. Koguchi, H. Kakibayashi, J. Appl. Phys. 74 (1993) 3162;

K. Haraguchi, K. Hiruma, M. Yazawa, T. Katsuyama, J. Electrochem. Soc. 153 (2006) C1;

J. Zou, M. Paladugu, H. Wang, G.J. Auchterlonie, Y.-N. Guo, Y. Kim, Q. Gao, H.J. Joyce, H.T. Tan, C. Jagadish, Small 3 (2007) 389. 
Figure Captions

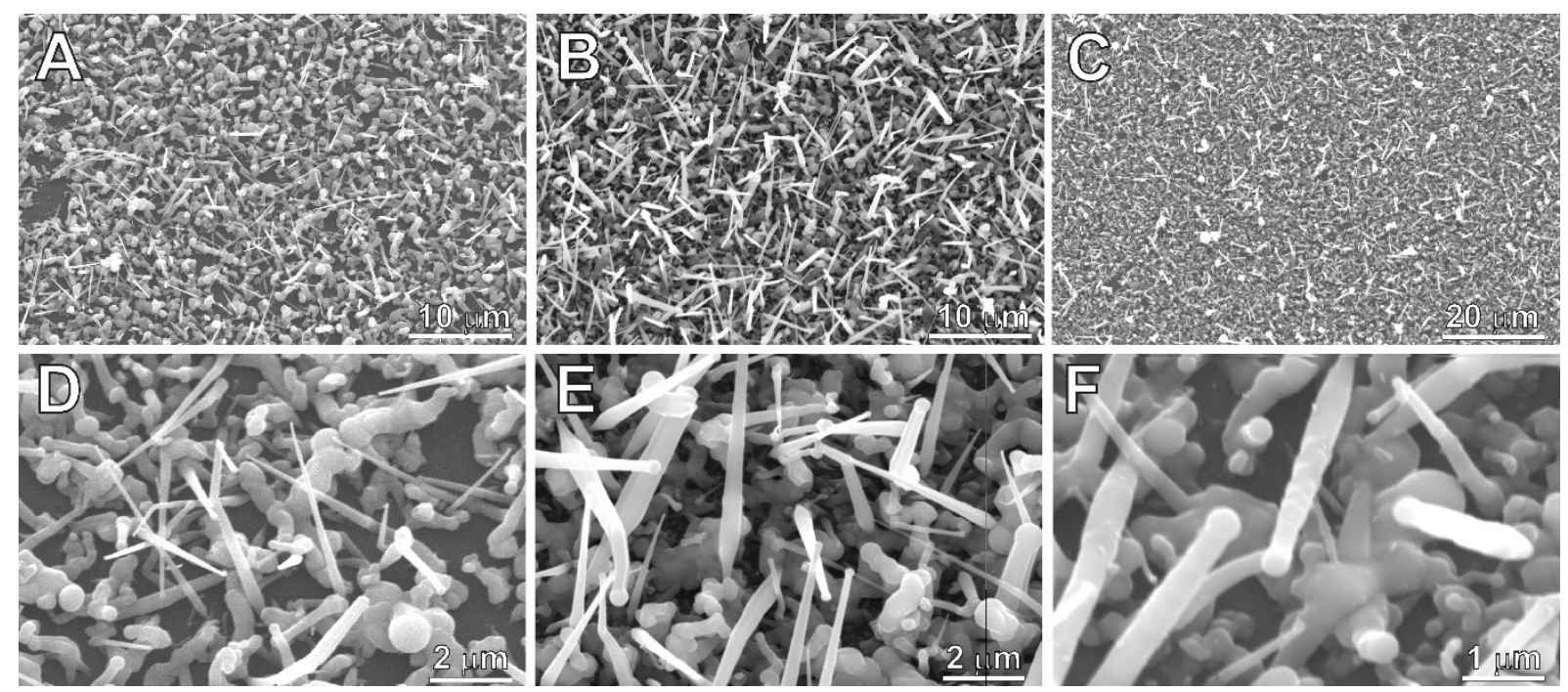

Figure 1a-f. SEM images showing GaSb nanowires obtained from 1 at $\mathrm{T}_{\mathrm{dec} .}=275^{\circ} \mathrm{C}(\mathbf{A}, \mathbf{D})$, $300{ }^{\circ} \mathrm{C}(\mathbf{B}, \mathbf{E})$, and $325^{\circ} \mathrm{C}(\mathbf{C}, \mathbf{F})$, respectively.

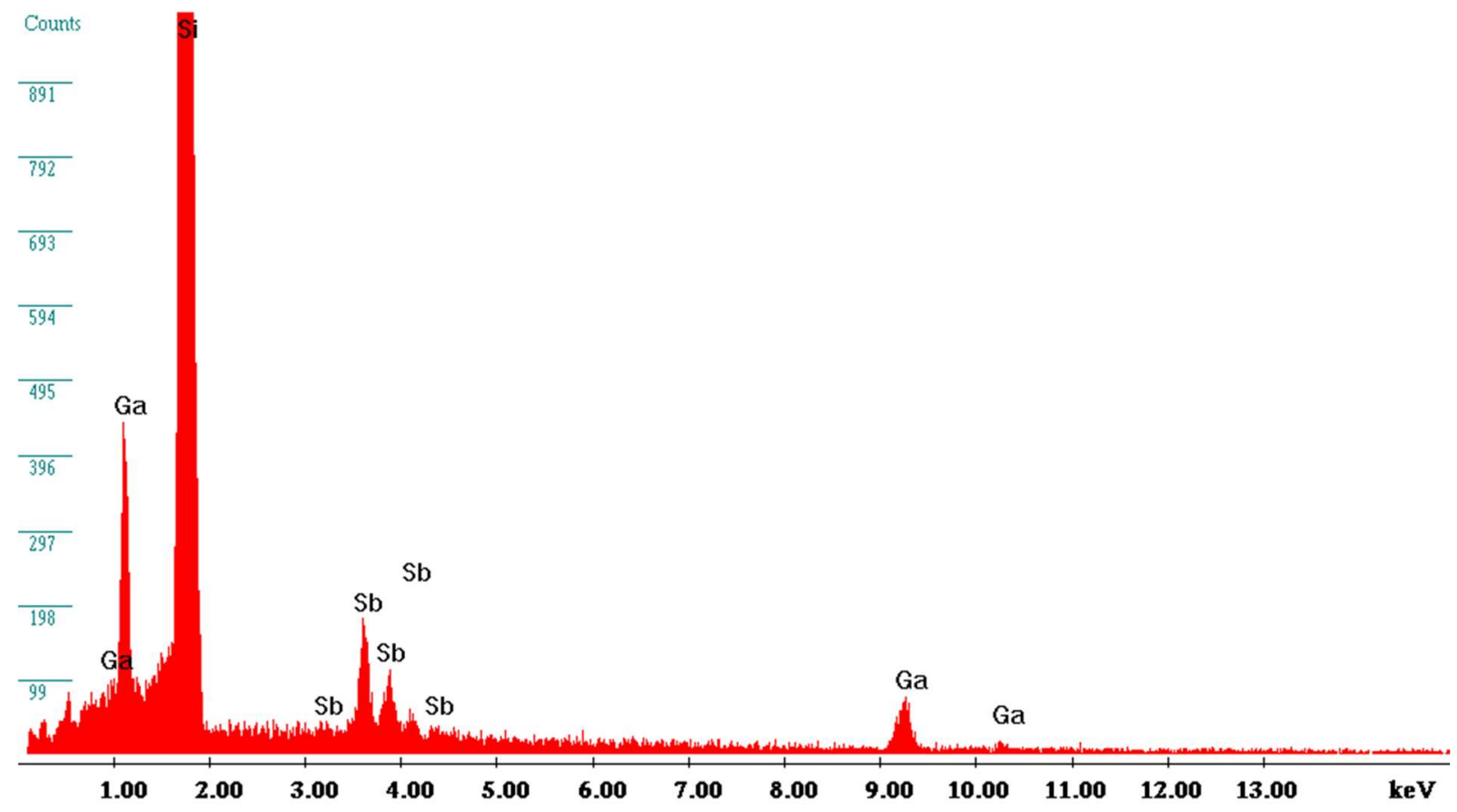

Figure 02. EDX spectra of GaSb nanowires obtained from (1). 

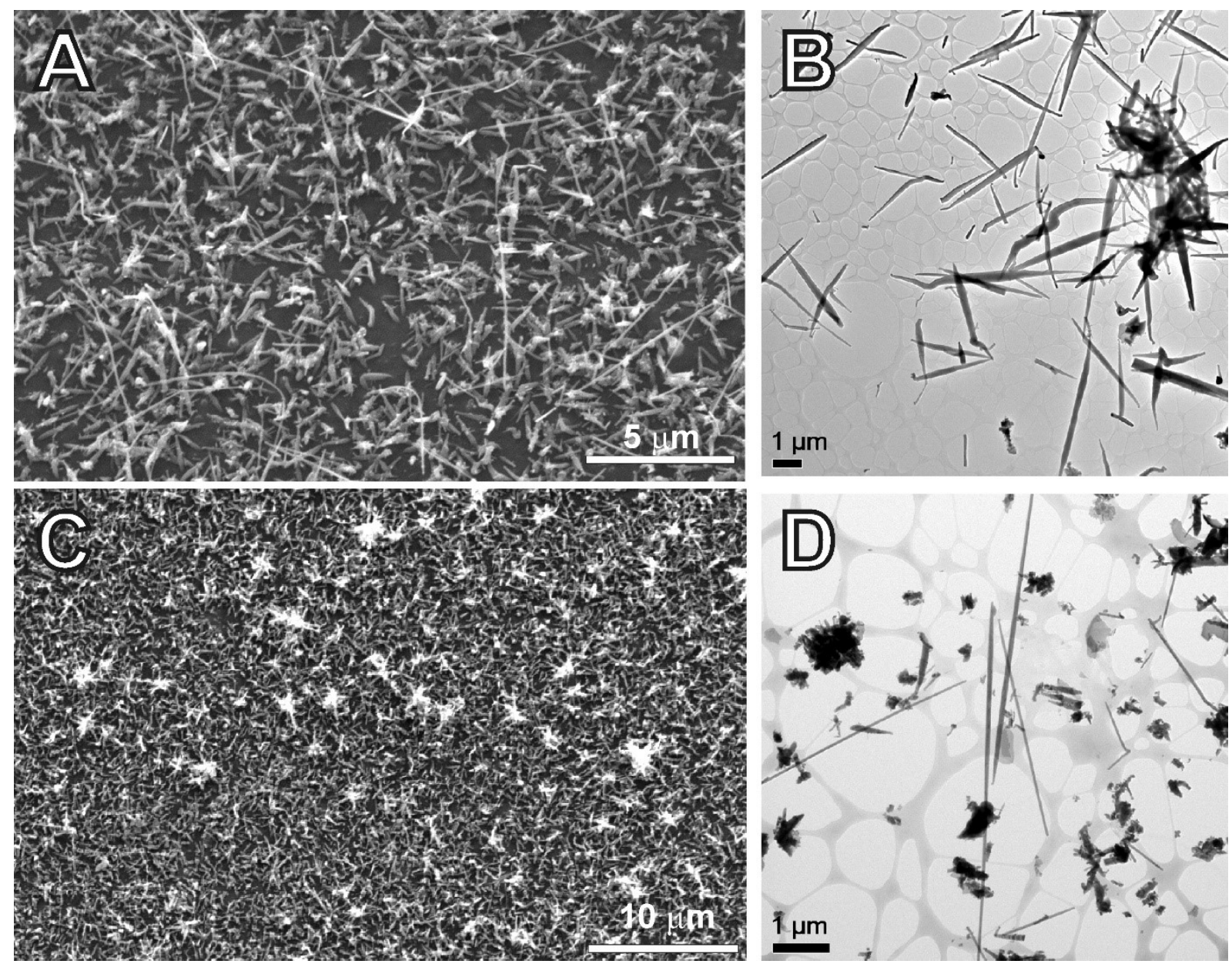

Figure 3a-d. SEM (left) and TEM images (right) of GaSb nanowires obtained from (2) at $\mathrm{T}_{\text {dec. }}=250{ }^{\circ} \mathrm{C}$ (top) and $400{ }^{\circ} \mathrm{C}$ (bottom), respectively. Image $\mathbf{D}$ clearly shows the formation of dendritic-like GaSb whiskers.
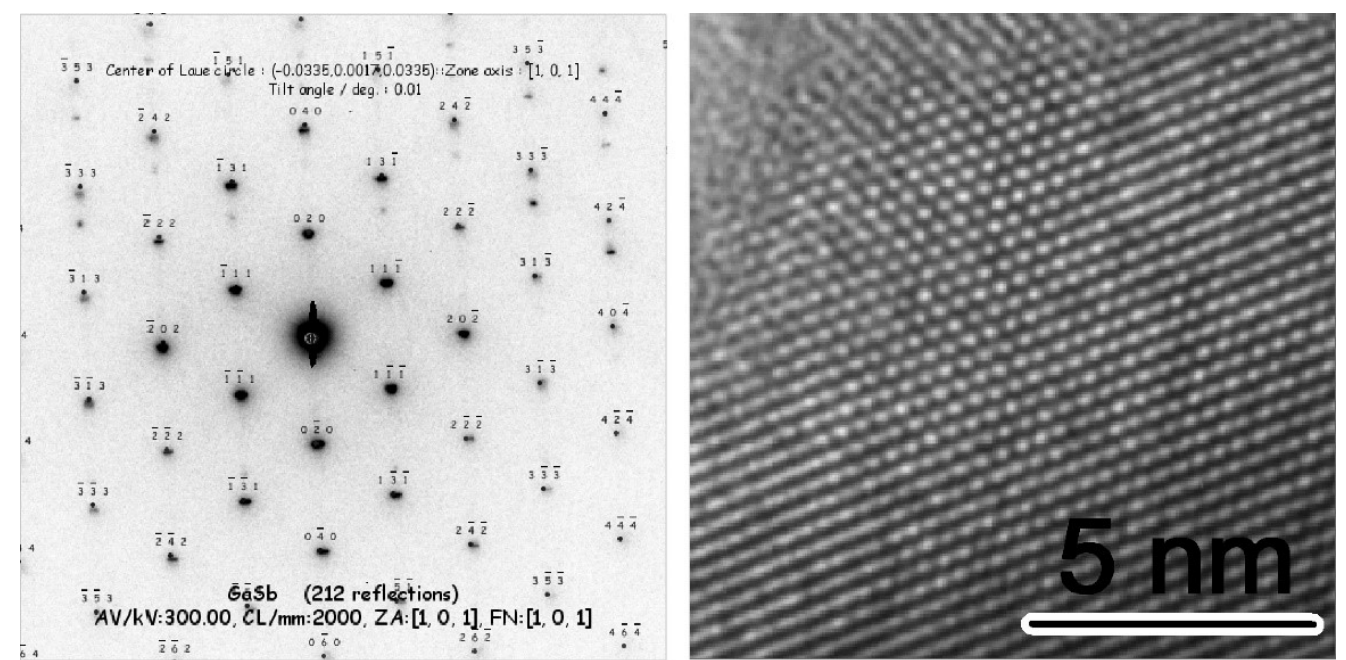

Figure 04. SAED pattern with simulation as an overlay ${ }^{[27]}$ and HRTEM image of of GaSb nanowires obtained from (2) at $\mathrm{T}_{\text {dec. }}=250{ }^{\circ} \mathrm{C}$ in $<110>$ zone axis. The indicated distances of 353 and $305 \mathrm{pm}$ correspond to $\{111\}$ and $\{200\}$ lattice fringes, respectively. 

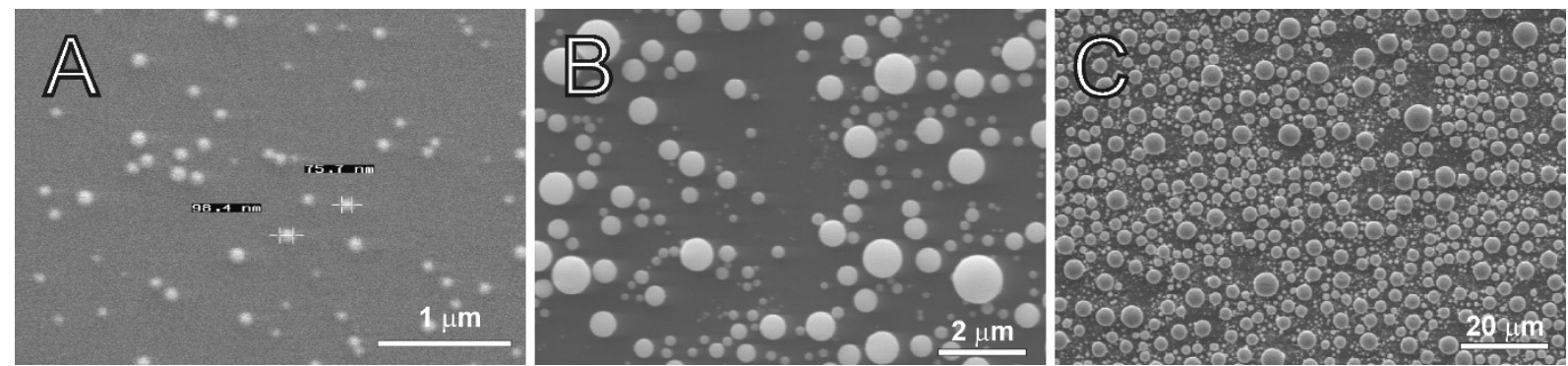

Figure 5a-c. SEM images showing Ga droplets formed at different decomposition temperatures $\left(\mathrm{T}_{\text {substrate }}=400{ }^{\circ} \mathrm{C} \mathrm{A}, \mathbf{B} ; \mathrm{T}_{\text {substrate }}=500{ }^{\circ} \mathrm{C} \mathrm{C}\right)$ and deposition times $\left(\mathrm{t}_{\text {dep }}(\mathrm{Ga})=5\right.$ $\sec \mathbf{A} ; 10 \sec \mathbf{B} ; 30 \sec \mathbf{C})$.
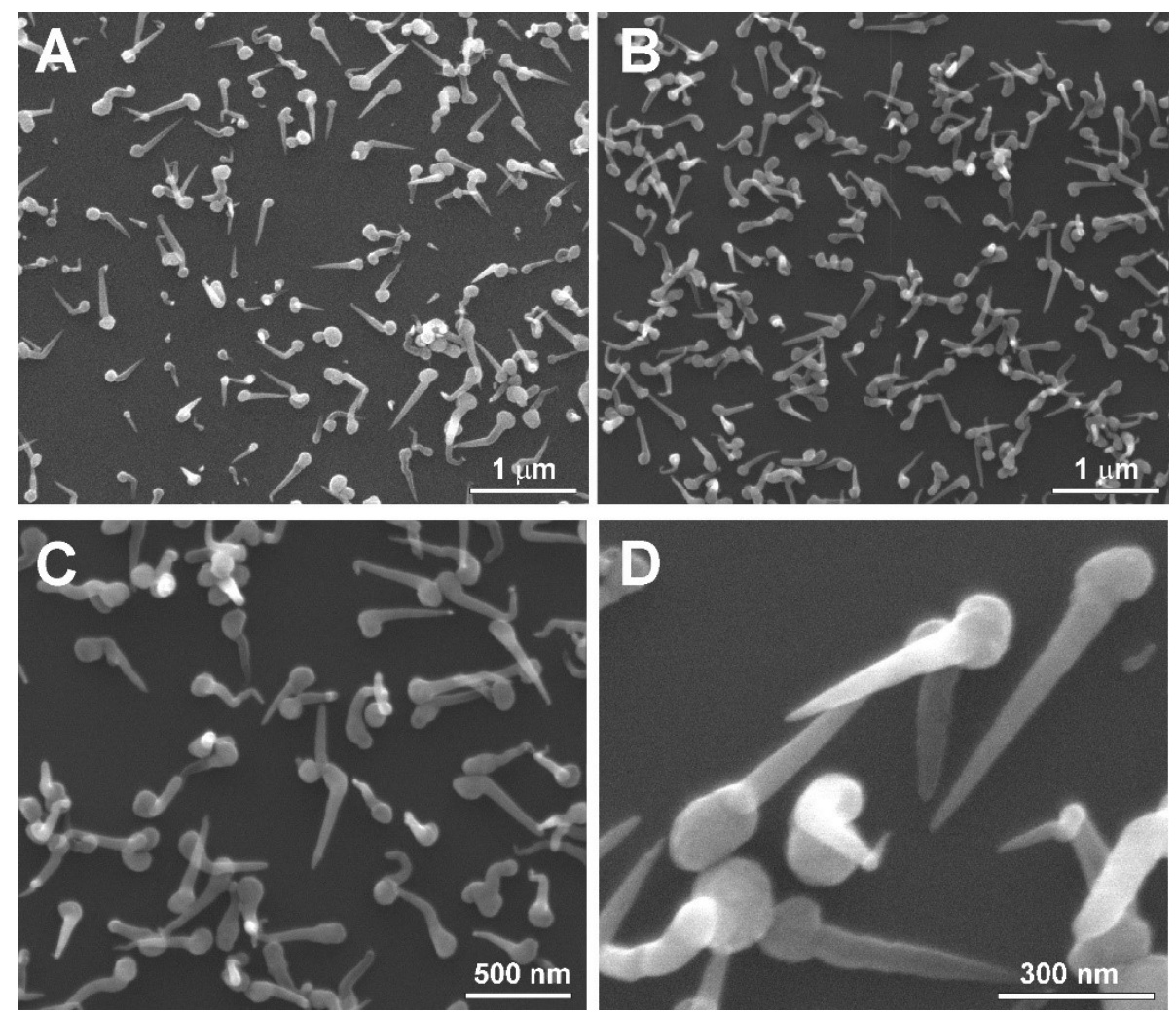

Figure 6a-d. SEM images showing tapered GaSb nanowires formed at $\mathrm{T}_{\text {substrate }}=250{ }^{\circ} \mathrm{C}$ with different deposition times $\left(t_{\text {dep. }}\left(\operatorname{Sb}_{2} E_{4}\right)=90 \min \mathbf{A}, \mathbf{C} ; 120 \mathrm{~min} \mathbf{B}, \mathbf{D}\right)$. 


\section{DuEPublico}

This text is made available via DuEPublico, the institutional repository of the University of Duisburg-Essen. This version may eventually differ from another version distributed by a commercial publisher.

DOI: $\quad$ 10.1016/j.jcrysgro.2010.01.026

URN: urn:nbn:de:hbz:464-20201104-074717-6

This is the "Authors Accepted Manuscript" of an article published in: Journal of Crystal Growth, Volume 312, Issue 9, 15 April 2010, Pages 1475-1480. The final version may be found at: https://doi.org/10.1016/j.jcrysgro.2010.01.026

cc (†) $\odot$ This work may be used under a Creative Commons Attribution CC NC ND NonCommercial - NoDerivatives 4.0 License (CC BY-NC-ND 4.0) 